\title{
Synthesis of the Flavonoid-Induced Lipopolysaccharide of Rhizobium Sp. Strain NGR234 Requires Rhamnosyl Transferases Encoded by Genes rgpF and wbgA
}

\author{
Silvia Ardissone, ${ }^{1}$ K. Dale Noel, ${ }^{2}$ Mitchell Klement, ${ }^{2}$ William J. Broughton, ${ }^{1}$ and William J. Deakin ${ }^{1}$ \\ ${ }^{1}$ Laboratoire de Biologie Moléculaire des Plantes Supérieures (LBMPS), Université de Genève, 30 Quai Ernest-Ansermet, \\ Sciences III, 1211 Genève 4, Switzerland; ${ }^{2}$ Department of Biology, Marquette University, Milwaukee, WI 53233, U.S.A.
}

Submitted 31 May 2011. Accepted 13 July 2011.

In the presence of flavonoids, Rhizobium sp. strain NGR234 synthesizes a new lipopolysaccharide (LPS), characterized by a rhamnan $\mathrm{O}$-antigen. The presence of this rhamnoserich LPS is important for the establishment of competent symbiotic interactions between NGR234 and many species of leguminous plants. Two putative rhamnosyl transferases are encoded in a cluster of genes previously shown to be necessary for the synthesis of the rhamnose-rich LPS. These two genes, $w b g A$ and $\operatorname{rgpF}$, were mutated. The resulting mutant strains synthesized truncated rough LPS species rather than the wild-type rhamnose-rich LPS when grown with flavonoids. Based on the compositions of these purified mutant LPS species, we inferred that RgpF is responsible for adding the first one to three rhamnose residues to the flavonoid-induced LPS, whereas WbgA is necessary for the synthesis of the rest of the rhamnan $O$ antigen. The NGR234 homologue of $\operatorname{lps} B$, which, in other bacteria, encodes a glycosyl transferase acting early in synthesis of the core portion of LPS, was identified and also mutated. LpsB was required for all the LPS species produced by NGR234, in the presence or absence of flavonoids. Mutants (i.e., of $\operatorname{lps} B$ and $\operatorname{rgpF}$ ) that lacked any portion of the rhamnan O-antigen of the induced LPS were severely affected in their symbiotic interaction with Vigna unguiculata, whereas the NGR $\Omega w b g A$ mutant, although having very few rhamnose residues in its LPS, was able to elicit functional nodules.

Current address for W. J. Deakin: Laboratory 4-760, Lipoprotein Research Group, Clinical Diabetes Unit, Service of Diabetes, Endocrinology and Nutrition, University Hospital, 4 Rue Gabrielle-Perret-Gentil, 1211 Geneva-14, Switzerland.

Current address for S. Ardissone: Department of Microbiology and Molecular Medicine, CMU, 1 rue Michel Servet, University of Geneva, $\mathrm{CH}-$ 1211 Geneva 4, Switzerland.

Current address for W.J. Broughton: (BAM) Bundesanstalt für Materialforschung und -prüfung, Abteilung 4, Fabeckstrasse 62, 14195 Berlin, Germany.

Corresponding authors: K. D. Noel; E-mail: dale.noel@marquette.edu; Telephone: +1.414.288.1475; Fax: +1.414.288.7357; and W. J. Deakin; E-mail:wdeakin@live.fr; Telephone: +41 2237293 03; Fax: +41 22372 9840.

* The $\boldsymbol{e}$-Xtra logo stands for "electronic extra" and indicates that three supplementary figures and two supplementary tables are published online.
Interactions between rhizobia and leguminous plants lead to root nodules in which the resident bacteria carry out nitrogen fixation for the benefit of the plant. Nodule development and the entry of rhizobia into them require a complex molecular dialog. Initially, flavonoids exuded into the rhizosphere by legume roots are sensed by compatible rhizobia, triggering the production of rhizobial signal molecules, including Nod factors that induce nodule organogenesis (Broughton et al. 2000; Jones et al. 2007). Additional rhizobial molecules, principally surface polysaccharides and secreted proteins, often are also required for successful invasion of the developing nodule (Deakin and Broughton 2009; Gibson et al. 2008).

Rhizobium sp. strain NGR234 (hereafter NGR234) is capable of nodulating more than 120 legume genera (Pueppke and Broughton 1999). One property facilitating the broad host range of this strain is that it senses numerous flavonoids to activate the regulatory cascade that produces symbiotic signal molecules (Kobayashi et al. 2004). Important also are the range and quantities of Nod factors, surface polysaccharides, and secreted proteins synthesized in response to flavonoids (Broughton et al. 2000).

The surface polysaccharide most commonly shown to be required in rhizobial symbiosis is lipopolysaccharide (LPS) (Becker et al. 2005). LPS is the major component of the outer leaflet of the outer membrane of gram-negative bacteria. It exists in two general forms, consisting of a lipid A along with a core oligosaccharide termed rough (R)-LPS, or with an additional O-antigen polysaccharide to create smooth (S)-LPS. Rhizobial mutants impaired in correct LPS assembly are frequently unable to establish effective, nitrogen-fixing, symbioses (Becker et al. 2005). For example, LpsB is a glycosyl transferase required at an early stage of core assembly, and its mutation in Sinorhizobium meliloti restricts the symbiosis to the formation of only nonfunctional (pseudo) nodules (Campbell et al. 2002). Mutants of Rhizobium etli deficient in O-antigen production similarly induce only pseudonodules on Phaseolus vulgaris hosts (Cava et al. 1989; Noel et al. 1986).

Given the importance of LPS in the establishment of functional nodules, it is not surprising that numerous reports describe changes in LPS structure during symbiotic interactions. One notable example is the increase in hydrophobicity of $R$. leguminosarum LPS during bacteroid development (D'Haeze et al. 2007; Kannenberg and Carlson 2001). Furthermore, changes to rhizobial LPS can be induced by plant exudates or purified flavonoids, as described for R. etli (Noel et al. 2004; Ojeda et al. 2010) and S. fredii USDA205 (Reuhs et al. 1994). The most 
dramatic change so far observed is the synthesis of a new LPS species upon flavonoid induction by NGR234 (Reuhs et al. 2005). This flavonoid-induced (Fi)-S-LPS is characterized by the presence of a rhamnan $O$-antigen, consisting of a trisaccharide repeating unit: [-3)--L-Rhap-(1,3)--L-Rhap-(1,2)--L-Rhap(1-]n (Reuhs et al. 2005).

Several genes encoding enzymes required for the synthesis of the Fi-S-LPS are found in a locus on the symbiotic plasmid of NGR234 (Fig. 1) (Freiberg et al. 1997). Mutations within some of these genes have been described and two mutants that abolish production of the Fi-S-LPS have been characterized: NGR $\Omega$ fix $F$ and NGR $\Delta r m l B-w b g A$. Both are impaired in proper nodule induction on many legume species (Broughton et al. 2006; Marie et al. 2004; Reuhs et al. 2005). The function of FixF is unknown, but one possibility is that it is involved in the export of some portion of the Fi-S-LPS (Broughton et al. 2006; Reuhs et al. 2005). In the case of NGR $\Delta r m l B-w b g A$, the nature of the mutation led to the deletion of an operon of four genes, $r m l B, r m l D$, $r m l A$ and $w b g A$. The three enzymes encoded by $r m l B, r m l D$, and $r m l A$ act in the conversion of TDP-glucose to TDP-rhamnose; thus, their inactivation blocks rhamnose production, most likely leading to the observed absence of rhamnan $O$-antigen (Broughton et al. 2006). In the presence of flavonoids, however, NGR $\Delta r m l B$ - $w b g A$ synthesizes a second R-LPS species that shows higher mobility with polyacrylamide gel electrophoresis (PAGE) (Broughton et al. 2006). This genetic locus is defined by regulatory sites known as nod boxes (NB) and tts boxes (TB) (Fig. 1), DNA binding sites for regulatory proteins in the wellcharacterized NodD1-controlled regulatory cascade of NGR234, which includes the TtsI protein when a TB is involved. Both fix $F$ (via an NB) and the $r m l B-w b g A$ operon (via a TB) are induced by flavonoids through this system (Kobayashi et al. 2004; Marie et al. 2004; Wassem et al. 2008).

The genetic locus shown in Figure 1 includes two genes, $w b g A$ and $\operatorname{rgpF}$ (previously annotated as $\mathrm{y} 4 \mathrm{gN}$ ), which potentially encode rhamnosyl transferases and could catalyze the formation of the rhamnan $O$-antigen. Although $\mathrm{WbgA}$ would have been absent in NGR $\Delta r m l B-w b g A$, its exact role may have been masked by the co-mutation of $r m l B, r m l D$, and $r m l A$. WbgA is predicted to have two rhamnosyl transferase domains, with differing glycosyl-linkage specificity (Supplementary Fig. S1A). Furthermore, at the amino terminus is a third putative glycosyl transferase domain, although homology searches give no clear indication of the possible substrate of this domain. The rhamnosyl transferase domain of RgpF was originally thought to be nonfunctional because it is truncated, based upon homology to RgpF of Streptococcus sp., the archetypal member of this family (Broughton et al. 2006). Subse- quently, the active component of the domain has been shortened, creating an RgpF-like superfamily domain, to which RgpF of NGR234 fits (Supplementary Fig. S2) (Schmeisser et al. 2009). In this work, we studied the effects of mutations in these two putative glycosyl transferase genes on the synthesis of the Fi-S-LPS of NGR234.

It has been proposed that the rhamnan $O$-antigen is added to a modified core (Reuhs et al. 2005). In S. meliloti, LpsB is believed to be required early in the synthesis of the LPS core structure. With the expectation that it might play the same role in NGR234, lpsB was mutated as an initial step in the determination of how early in the synthesis of the Fi-S-LPS the core modification may occur.

The major LPS species synthesized by the three mutants were analyzed. After differences in the residual LPS of all three mutants were observed, the effects of these mutations on nodulation of the legume Vigna unguiculata were assessed.

\section{RESULTS}

Mutation of $\operatorname{lpsB}, \operatorname{rgpF}$, and $\operatorname{wbgA}$.

Mutations in $\operatorname{rgpF}$ and $w b g A$ were created by the insertion of $\Omega$ cassettes into each gene (discussed below) (Fig. 1). The organization of the lpsBEDC locus, identified in the NGR234 genome, is very similar to that of $S$. meliloti 1021 (Lagares et al. 2001) and the homology between encoded enzymes is very high (Fig. 2; Supplementary Table S1). Mutation of $\operatorname{lps} B$ was performed by inserting an $\Omega$ cassette into the corresponding open reading frame (discussed below) (Fig. 2). The double mutants NGR $\Delta r m l B-w b g A \Omega l p s B$ and NGR $\Delta r m l B-w b g A \Omega f i x F$ were also created (discussed below).

The LPS profiles of these mutants, grown in rhizobial minimal media (RMS) or RMS supplemented with apigenin, were checked by sodium dodecyl sulfate (SDS)-PAGE and compared with those of NGR234 as well as NGR $\Omega$ fixF and NGR $\Delta r m l B$ $w b g A$, two mutants known to not synthesize the Fi-S-LPS (Broughton et al. 2006). In the absence of apigenin (Fig. 3A), NGR $\Omega$ rgpF and NGR $\Omega w b g A$ produced the same LPS species as NGR234. NGR $\Omega$ lps B, however, produced species of S-LPS and R-LPS with a higher mobility than those of the wild-type strain.

SDS-PAGE of LPS after the strains were grown in the presence of apigenin (Fig. 3B) showed that only NGR234 produced the distinctive smear of the Fi-S-LPS (Fig. 3B, indicated by a vertical line). NGR $\Omega$ lps $B$ presented the same LPS profile as that when grown without flavonoids (Fig. 3A and B, compare lanes 2). Of specific importance to this study, apigenin treatment of this mutant did not alter the SDS-PAGE LPS pro-

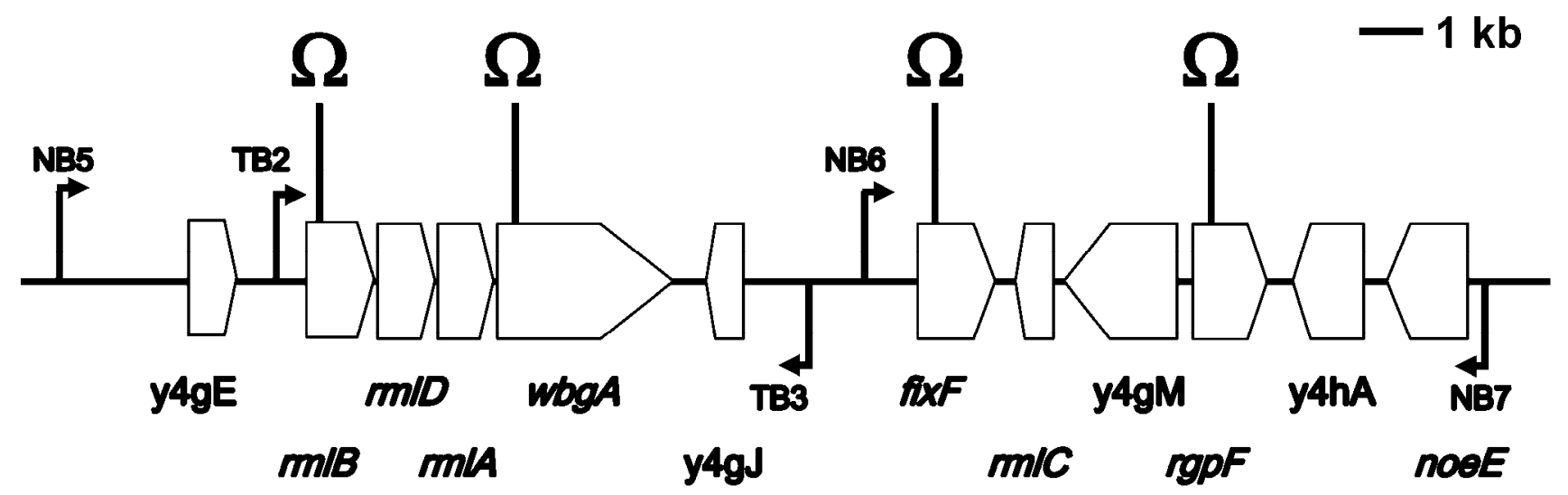

Fig. 1. The nod box 5-nod box 7 cluster on the symbiotic plasmid of NGR234. Genes are indicated by block arrows. Positions of the cis elements, nod boxes (NB), and tts boxes (TB) are indicated by arrowheads. Sites of insertion of $\Omega$ interposons used in this study are also indicated. 
file. The Fi-S-LPS was also not evident in extracts from either NGR $\Omega r g p F$ or NGR $\Omega w b g A$, although both mutants displayed a variety of minor S-LPS species. In fact, NGR $\Omega r g p F$ showed an LPS profile very similar to that of NGR $\Delta r m l B-w b g A$, including a high-mobility R-LPS band, whereas NGR $\Omega w b g A$ synthesized a different high-mobility R-LPS species (which was not resolved completely from the major R-LPS species). The R-LPS species that appeared after induction in these mutants are indicated by asterisks in Figure 3B.

LPS extracted from the double mutants NGR $\Delta r m l B$ $w b g A \Omega$ fix $F$ and NGR $\Delta r m l B$-wbgA $\Omega$ lps $B$ were also analyzed by SDS-PAGE (Fig. 3). Cultures of NGR $\Delta r m l B-w b g A \Omega f i x F$ grown in the absence of flavonoids produced LPS profiles identical to NGR234. However, after flavonoid induction, NGR $\Delta r m l B-w b g A \Omega$ fixF showed the same LPS profile as NGR $\Omega$ fix $F$. Regardless of the presence or absence of apigenin, NGR $\Delta r m l B$-wbgA $\Omega$ lps $B$ synthesized LPS indistinguishable from that of NGR $\Omega$ lps $B$.

To assess KPS production by these strains, identical SDSPAGE gels were migrated in parallel and stained with Alcian blue. By this criterion, the KPS profiles of all mutants were not obviously altered compared with the wild-type strain in the presence or absence of apigenin (data not shown).

\section{Transcriptional regulation of $r g p F$.}

The analysis of NGR $\Omega$ rgpF showed that $\mathrm{RgpF}$ must play a role in the production of the Fi-S-LPS. Because fixF and the $r m l B-w b g A$ operon are induced by flavonoids (Kobayashi et al. 2004; Marie et al. 2004; Wassem et al. 2008), we assessed whether $r g p F$ is also subject to the same regulation pattern. To do this, the promoter region of $\mathrm{rgpF}$ was cloned upstream of green fluorescent protein (GFP) in the broad-host-range plasmid pPROBE-GT (discussed below). NGR234 strains carrying the different promoter::GFP constructs were grown in RMS with and without apigenin and fluorescence was measured after 24, 48, and $72 \mathrm{~h}$. At all times postinduction, the rgpF promoter was unaffected by the presence of apigenin, showing only constitutive expression approximately 10-fold lower than the fixF promoter (data not shown).

\section{LPS composition analysis.}

Wild-type and mutant strains were grown in preparative volumes of RMS, in the presence or absence of the inducing compound apigenin. LPS was extracted from harvested cells and purified by two steps of gel chromatography in which the very different conditions allow separations based on different size properties of LPS: aggregated molecules in one case and possibly monodisperse molecules in the second (Gudlavalleti and Forsberg 2003; Peterson and McGroarty 1985; Reuhs et al. 2005). The last step of this purification (deoxycholate [DOC]- sephadex G150 chromatography) allowed separation of the LPS into subtypes, such that S-LPS was separated from R-LPS and certain R-LPS subtypes were substantially separated from each other (Fig. 4, lanes 3, 4, 6 to 9).
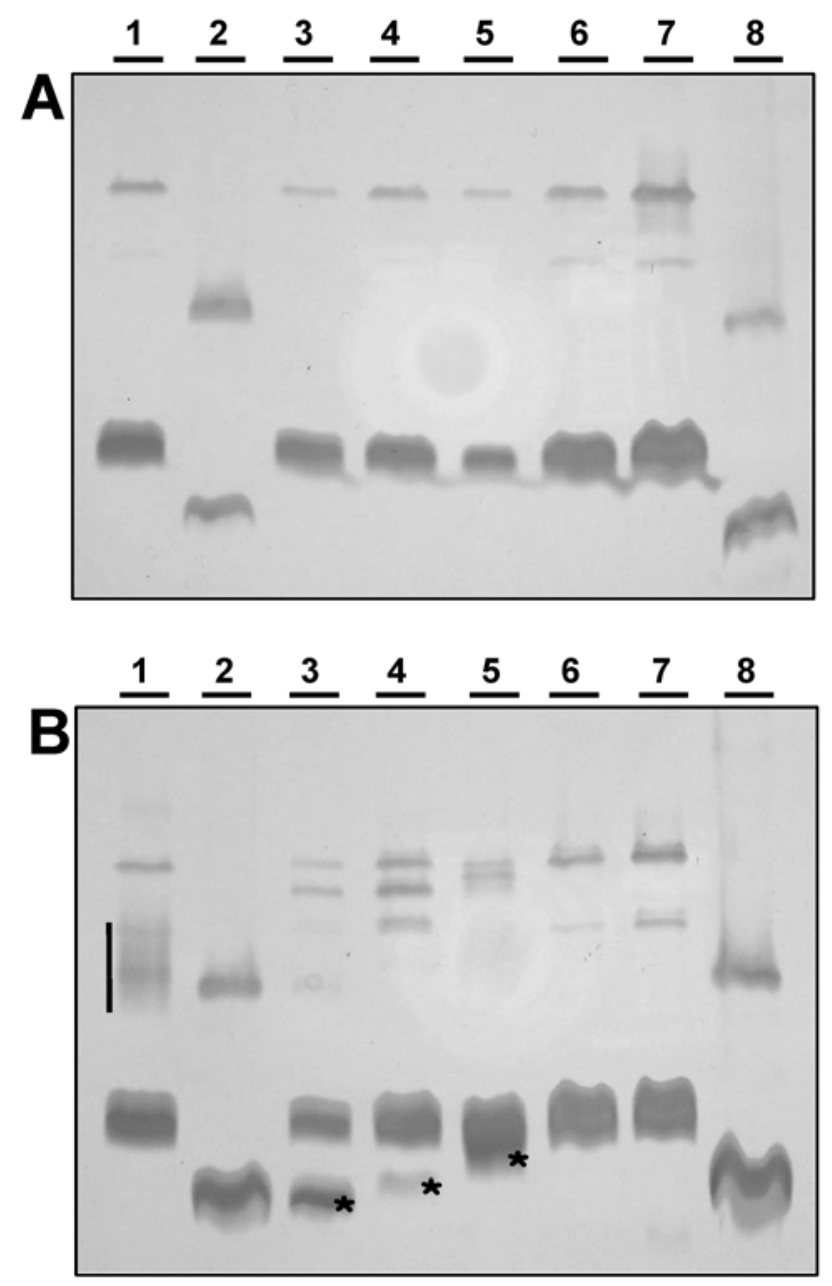

Fig. 3. Lipopolysaccharide (LPS) profiles of NGR234 and derivative mutants. Sodium dodecyl sulfate polyacrylamide gel electrophoresis analysis of extracted LPS, synthesized by NGR234 and various mutant strains grown in the $\mathbf{A}$, absence or $\mathbf{B}$, presence of apigenin. Flavonoid-induced smooth LPS species synthesized by NGR234 are indicated by a vertical line (B, lane 1). Additional (high-mobility) rough LPS species produced by the NGR $\Delta r m l B-w b g A, \mathrm{NGR} \Omega r g p F$, and NGR $\Omega w b g A$ mutants in the presence of apigenin are indicated by asterisks. Lane 1, NGR234; lane 2, $\mathrm{NGR} \Omega l p s B$; lane 3 , NGR $\triangle r m l B$ - wbgA; lane 4, NGR $\Omega \operatorname{rgp} F$; lane 5 , NGR $\Omega w b g A$; lane 6, NGR $\Omega$ fix F ; lane 7, NGR $\Delta r m l B$-wbgA $\Omega$ fix F ; lane 8, NGR $\Delta r m l B-w b g A \Omega l p s B$

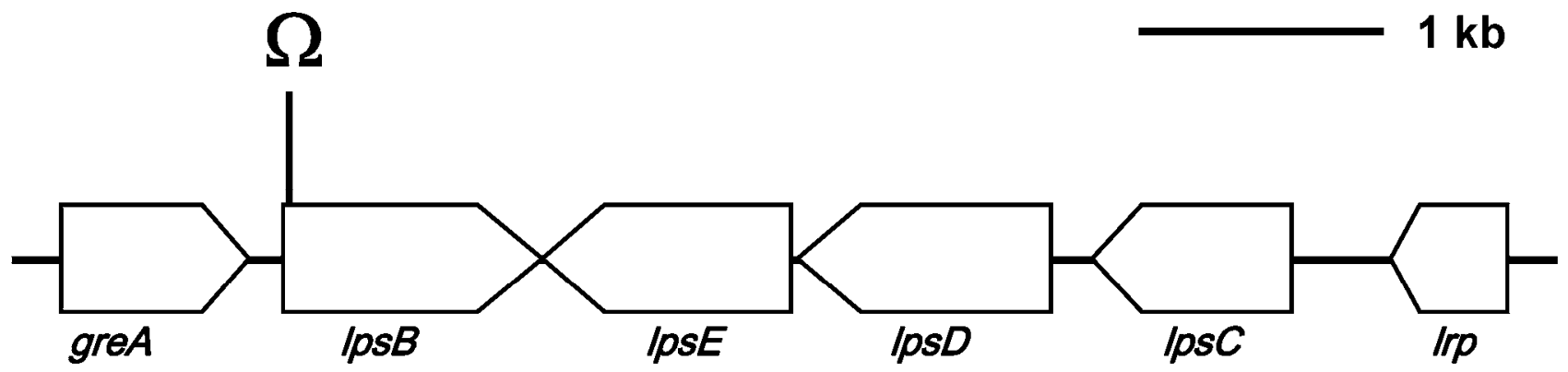

Fig. 2. lps $B$, lpsE, lpsD, and lps $C$ gene cluster of NGR234. The organization of the NGR234 lpsB, lpsE, lpsD, and lpsC genes (indicated by block arrows) is the same as that of Sinorhizobium meliloti 1021. In both cases, the lpsB, lpsE, lpsD, and lpsC locus is flanked by greA and $\operatorname{lrp}$. GreA is a transcription elongation factor. Lrp is a predicted transcriptional regulator (AsnC superfamily) and Lrp of NGR234 is 99\% similar to the S. meliloti homologue. The insertion site of the $\Omega$ interposon within $l p s B$ is indicated. 
NGR234. As observed in prior studies (Broughton et al. 2006; Reuhs et al. 2005), R-LPS was the predominant LPS of uninduced cultures (Fig. 3A, lane 1 and Fig. 4, lane 1). The RLPS purified from induced cultures not only migrated very similarly on SDS-PAGE (Fig. 4, lanes 1 and 4) but also had essentially the same sugar and fatty acid composition (Table 1, rows 1 and 4). The composition of purified Fi-S-LPS (Fig. 4, lane 3) differed from the R-LPS by having a high content of rhamnose, a small amount of 3-O-methylrhamnose, and decreased uronic acids, as previously reported (Reuhs et al. 2005), as well as the possibility of one additional residue of Kdo and GlcN (Table 1, row 3).

$N G R \Omega$ lpsB. The composition of R-LPS purified from NGR $\Omega$ lpsB (Fig. 4, R-LPS ${ }_{\text {lpsB }}$ ) was consistent, with its core oligosaccharide being highly truncated. Only Kdo and GlcN were present in near-normal (i.e., relative to the wild type) amounts, whereas no other sugars were detected in significant amounts.
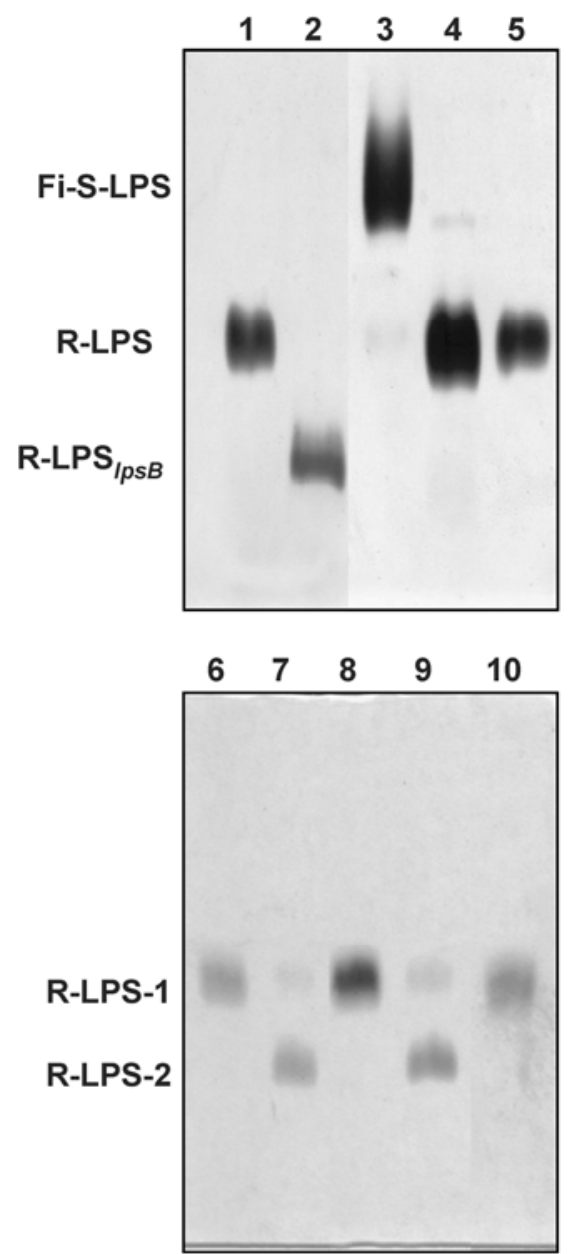

Fig. 4. Purified lipopolysaccharide (LPS) profiles of NGR234 and derivative mutants. Shown is sodium dodecyl sulfate polyacrylamide gel electrophoresis of the LPS in pooled fractions after the second chromatography step (deoxycholate [DOC]-G150). LPS in lanes 4, 7, and 9 were in fractions that emerged later on the same DOC-G150 column as those in lanes 3, 6, and 8, respectively. Lane 1, NGR234-noninduced rough (R)-LPS; lane 2, NGR $\Omega$ lps $B$-noninduced R-LPS (R-LPS ${ }_{\mathrm{lpsB}}$ ); lane 3, NGR234 flavonoid-induced smooth LPS (Fi-S-LPS); lane 4, R-LPS purified from induced NGR234 cultures; lane 5, R-LPS purified from induced NGR $\Omega$ fix $F$ cultures; lane 6, NGR $\Delta r m l B$ - $w b g A$-induced, first peak (R-LPS-1); lane 7, NGR $\Delta r m l B$-wbgA-induced, second peak (RLPS-2); lane 8, NGR $\Omega r g p F$-induced, first peak (R-LPS-1); lane 9, NGR $\Omega \operatorname{rgp} F$-induced, second peak (R-LPS-2); lane 10, NGR $\Omega w b g A$ induced, a mixture of R-LPS species.
$N G R \Omega$ fixF. After growth of NGR $\Omega$ fix $F$ with apigenin, the composition of its R-LPS, like its SDS-PAGE LPS profile, were similar to uninduced NGR234 (Figs. 3 and 4; Table 1).

$N G R \Delta \mathrm{rmlB}-w b g \mathrm{~A}$ and $N G R \Omega \mathrm{rgpF}$. After growth in the presence of apigenin, the LPS of these two strains could be separated during purification to give R-LPS-1 and R-LPS-2 (Fig. 4). The compositions of R-LPS-1 from NGR $\Delta r m l B$ $w b g A$ and NGR $\Omega$ rgpF were very similar to each other but distinct from the R-LPS-2 components which, in turn, were very similar from each strain (Table 1). The Kdo and GlcN contents of R-LPS-2 in both strains suggest the presence of an additional residue of each (Kdo and GlcN) per molecule compared with R-LPS-1. Importantly, no Rha was detected in either RLPS-1 or R-LPS- 2 from these two mutant strains.

$N G R \Omega w b g$ A. The two R- LPS synthesized in the presence of apigenin by this mutant (Fig. 3B, lane 5 and Fig. 4, lane 10) were not separated by the purification scheme and, for this reason, the entries in Table 1 are of the R-LPS mixture. NGR $\Omega w b g A$ was the only mutant to have any Rha in its RLPS. If one of the R- LPS in this mutant is the same as R-LPS1 of the above two mutants (and the R-LPS of NGR234) and the other one uniquely accumulates in NGR $2 w b g A$ (R$\left.\mathrm{LPS}_{\mathrm{wbgA}}\right)$, then the Rha content of the mixture implies at least two residues of Rha in R-LPS $S_{w b g A}$.

\section{Nodulation tests on $\boldsymbol{V}$. unguiculata.}

The symbiotic phenotypes of NGR $\Omega$ lps $B$, NGR $\Omega$ rgpF, and NGR $\Omega w b g A$ were tested with $V$. unguiculata (Table 2; Supplementary Fig. S3), a plant known to require the production of the Fi-S-LPS for efficient nodulation (Broughton et al. 2006; Reuhs et al. 2005). After 6 weeks of growth, plants inoculated with NGR $\Omega \operatorname{lps} B$ were small and yellow, as with the noninoculated controls, and pink nodules were rarely observed. NGR $\Omega$ rgpF showed a symbiotic phenotype very similar to NGR $\Delta r m l B-w b g A$ and NGR $\Omega$ fix $F$, with very few active (pink) nodules produced, and plants were always significantly smaller than those inoculated with NGR234. Unexpectedly, inoculation with NGR $\Omega w b g A$ resulted in relatively large, green plants with numerous pink fixing nodules, although the plants were smaller and possessed fewer pink nodules than those inoculated with NGR234. Nevertheless, considering all the parameters measured, plants inoculated with NGR $\Omega w b g A$ were significantly healthier than those inoculated with other Fi-S-LPSdeficient mutants (NGR $\Omega l p s B$, NGR $\Omega$ fix F, NGR $\Delta r m l B-w b g A$, and NGR $\Omega$ rgpF $)$ (Table 2).

\section{DISCUSSION}

Based on the homology of RgpF and WbgA to known rhamnosyl transferases, mutations of $r g p F$ and $w b g A$ were predicted to severely affect production of the rhamnan $O$-antigen portion of Fi-S-LPS. Results confirmed this prediction and provided clues to the different roles of these two proteins in $\mathrm{Fi}$ $\mathrm{S}$-LPS synthesis. Induced LPS from the $r g p F$ mutant closely resembled that of the $\triangle r m l B-w b g A$ mutant; both lacked rhamnose. On the other hand, composition of the induced R-LPS of $w b g A$ indicated at least two rhamnose residues per R-LPS ${ }_{w b g A}$ molecule. One explanation for these results is that $\mathrm{RgpF}$ acts first and, after at least one residue is added, $\mathrm{WbgA}$ is required for further addition of rhamnose residues.

A more refined but more speculative idea is that RgpF acts only in making the first addition and that $\mathrm{WbgA}$ is the processive polymerase that synthesizes the rest of the rhamnan $O$ antigen. One reason for this suggestion is that the attachment of the first rhamnose residue is seemingly to a different acceptor substrate, unlike any of the other rhamnose residues, particularly because the resulting polymer contains only rhamnose 
residues after that point. As described earlier, WbgA possesses two probable rhamnosyl transferase domains with different linkage specificities (Poon et al. 2008) which could synthesize the rhamnan $O$-antigen trisaccharide repeating unit: [-3)--LRhap-(1,3)--L-Rhap-(1,2)--L-Rhap-(1-]n. Alternatively, a third possible glycosyl transferase domain in the WbgA sequence may be responsible for the addition of one of the residues in the repeating unit.

There is no direct evidence for this model from experimental results at this point, however. Among other alternative models, one cannot exclude the formal possibility that RgpF and $\mathrm{WbgA}$ cooperate in a processive fashion, with $\mathrm{RgpF}$ catalyzing one linkage and WbgA the other two of each repeating unit. A complete uncertainty is what the acceptor for addition of the first rhamnose might be. This question may hinge on the rules for FixF-mediated synthesis, which are still to be revealed. Studies of homologous proteins to FixF, in other bacteria, have not arrived at a consensus opinion regarding their functionality (Whitfield 2006). However, the nature of the R-LPS produced by NGR $\Omega$ fix $F$ supports a role for FixF at a very early stage of Fi-S-LPS synthesis. There is no evidence for synthesis of any higher-mobility R-LPS in the fixF mutant. Furthermore, the double mutant NGR $\Delta r m l B$-wbgA $\Omega$ fixF presented the same LPS profile as NGR $\Omega$ fix $F$, implying that FixF is necessary for the production of R-LPS-2 by NGR $\Delta r m l B-w b g A$. Thus, FixF could bring about the addition of a specific residue during LPS synthesis which then commits the nascent LPS species to an eventual rhamnan $O$-antigen attachment (i.e., to become Fi-S-LPS).

LpsB is a homologue of $R$. leguminosarum $\mathrm{LpcC}$, which adds the first hexose to the second Kdo during LPS core synthesis (Kanipes et al. 2003). Reported compositions of S. meliloti LpsB mutants seem to conflict with this same function for LpsB in that bacterium (Campbell et al. 2002). By contrast, the results in this study with NGR $\Omega$ lpsB are compatible with LpsB playing the same role as LpcC; sugars other than Kdo and GlcN were not detected in significant amounts in LPS purified from NGR $\Omega l p s B$. In regard to the core of Fi-S-LPS, the SDS-PAGE profiles of $\mathrm{NGR} \Omega l p s B$ and NGR $\Delta r m l B-w b g A \Omega l p s B$ indicate that the core portion of the Fi-S-LPS is built on these same very early steps of core synthesis as in uninduced bacteria.

Mutants NGR $\Omega l p s B$, NGR $\operatorname{rgp} F$, and NGR $\Delta r m l B-w b g A$, whose induced LPS lacked any detectable rhamnose, were severely deficient in eliciting functional nodules within 6 weeks on V. unguiculata. However, NGR $\Omega w b g A$ was still capable of inducing enough functional nodules to sustain substantial plant growth in the absence of nitrate, even though R-LPS ${ }_{w b g A}$ is only slightly more glycosylated than R-LPS-2. Numerous explanations for the effects of R-LPS ${ }_{\mathrm{wbgA}}$ could be proposed, to correlate with the function or functions of the Fi-S-LPS in the infection of $V$. unguiculata by NGR234. To mention one possibility, the production of the Fi-S-LPS could replace or mask an exposed rhizobial surface component whose detection triggers plant defenses to block infection by NGR234. Then, the presence of R-LPS $S_{w b g A}$ permits a partial evasion from this detection and, thus, a reduced level of infection, seen by the production of fewer functional nodules.

However, the synthesis of Fi-S-LPS is not the only flavonoidinduced change to the surface polysaccharides of NGR234. There is also a reduction in the quantities of capsular (KPS) polysaccharide produced (Le Quéré et al. 2006). The loss of KPS would lead to a greater exposure of the Fi-S-LPS (or RLPS $_{\text {wbgA }}$ ) on the surface of NGR234, raising the possibility that Fi-S-LPS could be a ligand for a plant receptor to facilitate infection, as has been suggested for the LPS of $R$. etli CE166 (Noel et al. 2000). Partial components of this $R$. etli LPS permit infection to different extents, and the reduced structure of the RLPS $_{\text {wbga }}$ might be functioning in an analogous manner.

The production of the Fi-S-LPS by NGR234 may be required during infection of $V$. unguiculata root cells for numer-

Table 2. Nodulation of Vigna unguiculata by NGR234 and derivative mutants $^{\mathrm{a}}$

\begin{tabular}{|c|c|c|c|}
\hline Strain & $\begin{array}{c}\text { Number of } \\
\text { nodules }\end{array}$ & $\begin{array}{c}\text { Nodule weight } \\
\text { (mg) }\end{array}$ & $\begin{array}{l}\text { Dry weight } \\
\text { (mg) }\end{array}$ \\
\hline Control & 0 & 0 & $77( \pm 25)$ \\
\hline NGR234 & $50.8( \pm 5.5)$ & $565( \pm 123)$ & $858( \pm 338)$ \\
\hline $\mathrm{NGR} \Omega$ fix $F$ & $7.4 *( \pm 1.8)$ & $37 *( \pm 20)$ & $144 *( \pm 55)$ \\
\hline NGR $\Omega l p s B$ & $0.6^{*}( \pm 1.0)$ & $21 *( \pm 40)$ & $67 *( \pm 24)$ \\
\hline NGR $\Omega$ rgp $F$ & $8.3^{*}( \pm 1.8)$ & $81 *( \pm 28)$ & $122 *( \pm 24)$ \\
\hline $\mathrm{NGR} \Omega w b g A$ & $31.9 * \boldsymbol{\Delta}^{( \pm 9.8)}$ & $423^{\wedge}( \pm 194)$ & $599^{\wedge}( \pm 190)$ \\
\hline NGR $\Delta r m l B-w b g A$ & $1.8^{*}( \pm 1.2)$ & $12 *( \pm 14)$ & $85^{*}( \pm 36)$ \\
\hline
\end{tabular}

${ }^{a}$ Numbers listed are per plant. Nodulation tests were repeated at least twice, with six to eight plants being tested each time. Standard deviations from the means are indicated in parentheses. Statistical analyses (Student's $t$ test) were performed comparing each mutant with the wild-type strain; significant $(P \leq 0.01)$ differences are shown with an asterisk $(*)$. Data from NGR $\Omega w b g A$ were similarly compared with that of NGR $\Omega$ fix $F$, NGR $\Omega r g p F$, and NGR $\Delta r m l B-w b g A$ with significant $(P \leq 0.01)$ differences indicated by filled triangles $(\boldsymbol{\Lambda})$.

Table 1. Sugar and hydroxy fatty acid compositions ${ }^{\mathrm{a}}$

\begin{tabular}{|c|c|c|c|c|c|c|c|c|c|c|c|c|}
\hline \multirow[b]{2}{*}{ Strain } & \multirow[b]{2}{*}{ Ind $^{d}$} & \multirow[b]{2}{*}{$\mathbf{L P S}^{\mathbf{e}}$} & \multicolumn{6}{|c|}{ Sugars $^{b}$} & \multicolumn{4}{|c|}{ Hydroxy fatty acids ${ }^{c}$} \\
\hline & & & Rha & Glc & GalA & GlcA & Kdo & GlcN & $14: 0$ & $16: 0$ & 18:0 & 28:0 \\
\hline NGR234 & - & R-LPS & 0.0 & 3.7 & 1.4 & 1.1 & 2.0 & 1.9 & 2.0 & 0.5 & 0.8 & 0.6 \\
\hline $\mathrm{NGR} \Omega$ lps $B$ & - & R-LPS ${ }^{f}$ & 0.0 & 0.3 & 0.2 & 0.1 & 2.0 & 1.9 & 2.6 & 0.3 & 0.5 & 0.6 \\
\hline NGR234 & + & S-LPS & 32.1 & 4.0 & 0.2 & 0.3 & 3.9 & 2.7 & 1.8 & 0.5 & 0.7 & 1.0 \\
\hline NGR234 & + & R-LPS & 0.6 & 3.2 & 1.7 & 1.1 & 2.2 & 1.8 & 2.1 & 0.5 & 0.8 & 0.7 \\
\hline NGR $\Omega$ fix $F$ & + & R-LPS & 0.0 & 2.5 & 1.1 & 0.6 & 1.9 & 1.3 & 2.4 & 0.3 & 0.5 & 0.9 \\
\hline NGR $\Delta r m l B^{\mathrm{g}}$ & + & R-LPS-1 & 0.0 & 1.7 & 1.0 & 0.5 & 1.7 & 1.0 & 2.2 & 0.2 & 0.3 & 1.3 \\
\hline NGR $\Delta r m l B^{\mathrm{g}}$ & + & R-LPS-2 & 0.0 & 2.1 & 0.9 & 0.2 & 3.4 & 1.7 & 2.2 & 0.3 & 0.3 & 1.2 \\
\hline NGR $\Omega$ rgpF & + & R-LPS-1 & 0.0 & 2.4 & 1.0 & 0.6 & 1.6 & 1.2 & 2.4 & 0.3 & 0.5 & 0.9 \\
\hline $\mathrm{NGR} \Omega r g p F$ & + & R-LPS-2 & 0.0 & 3.1 & 0.7 & 0.3 & 2.6 & 2.4 & 2.3 & 0.3 & 0.5 & 1.0 \\
\hline NGR $\Omega w b g A$ & + & R-LPS ${ }^{\mathrm{h}}$ & 1.4 & 2.1 & 1.0 & 0.4 & 2.3 & 1.3 & 2.2 & 0.2 & 0.4 & 1.2 \\
\hline
\end{tabular}

${ }^{\mathrm{a}}$ Entries are the apparent molar contents of each component relative to the average hydroxy fatty acid content of one mole of lipid A (i.e., 4.0 mol of the fatty acids shown).

${ }^{\mathrm{b}} \mathrm{Gal}$ and Man were present in some samples in trace amounts, not shown. NGR234 smooth lipopolysaccharide (S-LPS) contained 3-O-methylRha (0.92 mol per 32 mol of Rha).

${ }^{c}$ Only the relative contents of the four major fatty acids are shown (14:0 is 3-OH-14:0, 16:0 is 3-OH-16:0, 18:0 is 3-OH-18:0, and 28:0 is 27-OH-28:0).

${ }^{\mathrm{d}}$ Induction: apigenin was present $(+)$ or absent $(-)$ during growth of the culture from which the LPS was purified.

e Noted LPS was the main constituent of that sample.

${ }^{\mathrm{f}}$ Truncated, high-mobility rough (R)-LPS [R-LPS $\left.{ }_{\text {lpsB }}\right]$ unique to NGR $\Omega$ lps $B$ mutants.

$\mathrm{g}$ Where NGR $\Delta r m l B$ refers to the NGR $\Delta r m l B$-wbgA mutant.

${ }^{\mathrm{h}}$ Mixture of two forms of R-LPS (flavonoid-induced R-LPS ${ }_{\mathrm{wbgA}}$ ). 
ous reasons. Nevertheless, the fact that an extremely truncated form of flavonoid-induced LPS allows NGR $\Omega w b g A$ to eventually overcome the barrier to infection encountered by the other mutants is a very interesting clue to the role of the Fi-S-LPS in symbiosis. Our work demonstrates that the presence of a complete rhamnan $O$-antigen per se is not essential for nodule formation. Most likely, the production (or partial production) of the Fi-S-LPS is just one component of an extensive change to the surface of NGR234 that facilitates successful infection of V. unguiculata.

\section{MATERIALS AND METHODS}

\section{General molecular and microbiological techniques.}

Standard molecular cloning techniques were used throughout (Ausubel et al. 1991; Sambrook et al. 1989). All strains and plasmids are listed in Table 3 and all oligonucleotide primers in Supplementary Table S2. Escherichia coli recombinants were grown at $37^{\circ} \mathrm{C}$ on Luria-Bertani medium (Sambrook et al. 1989). NGR234 and its derivatives were raised at $27^{\circ} \mathrm{C}$ for $40 \mathrm{~h}$ (unless specified) in RMS (Broughton et al. 1986) or tryptone yeast (TY) media (Beringer 1974). Ampicillin, gentamicin, kanamycin, rifampicin, and spectinomycin were added at concentrations of 100, 20 (10 for E. coli), 50,100, and $50 \mu \mathrm{g}$ $\mathrm{ml}^{-1}$, respectively. When appropriate, the flavonoid apigenin was added at $10^{-6} \mathrm{M}$ to induce NGR234 strains.

Mutation of $\operatorname{lps} B, \operatorname{rgpF}$, and $\operatorname{wbg} A$.

To obtain NGR $\Omega$ lps $B$, the polymerase chain reaction (PCR) with primers lpsB3 and lpsB4 was used to amplify a $1.5-\mathrm{kb}$ DNA fragment containing the $\mathrm{N}$-terminal part of $\operatorname{lps} B$ from genomic DNA of NGR234, which was cloned into pBluescript II $\mathrm{KS}^{+}$to create pKS-lpsB and then sequenced to verify PCR fidelity. An $\Omega$ interposon (Fellay et al. 1987) conferring resistance to spectinomycin was inserted into the internal EcoRV site located immediately after the start codon of $\operatorname{lps} B$. The mutated gene was then subcloned into the suicide vector pJQ200SK using ApaI and $X b a \mathrm{I}$ to create pJQ-lpsB $\Omega$ Sp.

To obtain NGR $\Omega \operatorname{rgpF}$, the PCR with primers rgpFfor and rgpFrev was used to amplify a 1.8 -kb DNA fragment containing rgpF from genomic DNA of NGR234, which was cloned into pBluescript II $\mathrm{KS}^{+}$to create pKS-rgpF and then sequenced

Table 3. Bacterial strains and plasmids

\begin{tabular}{|c|c|c|c|}
\hline Strain & Relevant characteristics $^{\mathrm{a}}$ & NBRC no. ${ }^{b}$ & Reference, source \\
\hline \multirow{2}{*}{\multicolumn{4}{|c|}{ supE44, $\Delta l a c \mathrm{U} 169(\Phi 80$ lacZ $\triangle \mathrm{M} 15)$, hsdR17, recA1, gyrA96, thi-1, relA1 }} \\
\hline & supE44, $\Delta l a c \mathrm{U} 169(\Phi 80$ lacZ $\Delta \mathrm{M} 15)$, hsdR17, recA1, gyrA96, thi-1, relA1 & na & BRL, Bethesda, MD, U.S.A. \\
\hline Rhizobium sp. strains & & & \\
\hline NGR234 & Broad-host-range bacterium isolated from nodule of Lablab purpureus, Rif $^{\mathrm{r}}$ & 101917 & Stanley et al. 1988 \\
\hline NGR $\Delta r m l B-w b g A$ & $\begin{array}{l}\text { NGR234 derivative in which the } 3.7-\mathrm{kb} E c o \mathrm{RV} \text { fragment containing } r m l B- \\
\text { wbgA was replaced by an } \Omega \text { cassette, } \mathrm{Rif}^{\mathrm{r}}, \mathrm{Km}^{\mathrm{r}}\end{array}$ & 101947 & Broughton et al. 2006 \\
\hline 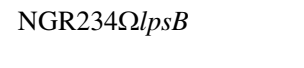 & $\begin{array}{l}\text { NGR234 derivative containing an } \Omega \text { cassette inserted into the } E c o R V \text { site of } \\
l p s B, \operatorname{Rif}^{\mathrm{r}} \mathrm{Sp}^{\mathrm{r}}\end{array}$ & 101956 & This work \\
\hline NGR $\Delta r m l B-w b g A \Omega l p s B$ & $\begin{array}{l}\text { NGR } \Delta r m l B \text {-wbgA derivative containing an } \Omega \text { cassette inserted into the } E c o \mathrm{RV} \\
\text { site of } l p s B, \mathrm{Rif}^{\mathrm{r}}, \mathrm{Sp}^{\mathrm{r}}, \mathrm{Km}^{\mathrm{r}}\end{array}$ & 106190 & This work \\
\hline NGR $\Delta r m l B-w b g A \Omega f i x F$ & $\begin{array}{l}\text { NGR } \Omega f i x F \text { derivative containing a deletion encompassing the } r m l B, r m l D, \\
r m l A \text {, and } w b g A \text { genes, } \operatorname{Rif}^{\mathrm{r}}, \mathrm{Sp}^{\mathrm{r}}, \mathrm{Km}^{\mathrm{r}}\end{array}$ & 106191 & This work \\
\hline NGR $\Omega$ rgpF & $\begin{array}{l}\text { NGR234 derivative containing an } \Omega \text { cassette inserted into the } X b a \text { I site of } \\
\operatorname{rgpF}, \operatorname{Rif}^{r} \mathrm{Sp}^{\mathrm{r}}\end{array}$ & 106192 & This work \\
\hline NGR $\Omega w b g A$ & $\begin{array}{l}\text { NGR234 derivative containing an } \Omega \text { cassette inserted into the } S p h \text { I site of } \\
w b g A, \operatorname{Rif}^{\mathrm{r}} \mathrm{Km}^{\mathrm{r}}\end{array}$ & 106193 & This work \\
\hline NGR $\Omega$ fix $F$ & $\begin{array}{l}\text { NGR234 derivative containing an } \Omega \text { cassette inserted into the EcoRI site of } \\
\text { fixF, } \text { Rif }^{\mathrm{r}} \mathrm{Sp}^{\mathrm{r}}\end{array}$ & 101924 & Reuhs et al. 2005 \\
\hline Plasmids & & & \\
\hline $\begin{array}{l}\text { pBluescript II } \mathrm{KS}^{+} \\
\text {pKS-lpsB }\end{array}$ & $\begin{array}{l}\text { High copy number ColEI-based phagemid, } \mathrm{Ap}^{\mathrm{r}} \\
\text { pBluescript KS+ derivative carrying a } 1.5-\mathrm{kb} \text { polymerase chain reaction (PCR) }\end{array}$ & $\ldots$ & Stratagene, La Jolla, CA, U.S.A. \\
\hline & fragment containing the $\mathrm{N}$-terminal part of $\operatorname{lps} B$ gene, $A p^{\mathrm{r}}$ & $\ldots$ & This work \\
\hline pKS-lps $B \Omega S p$ & pKS-lps $B$ derivative with an $\Omega-\mathrm{Sp}^{\mathrm{r}}$ interposon inserted into the unique & & \\
\hline pKS-rgpF & $\begin{array}{l}\text { EcoRV site of } l p s B, \mathrm{Ap}^{\mathrm{r}} \mathrm{Sp}^{\mathrm{r}} \\
\text { pBluescript KS+ derivative carrying a 1.8-kb PCR fragment containing the }\end{array}$ & $\ldots$ & This work \\
\hline pKS-rgpF $\Omega \mathrm{Sp}$ & $\begin{array}{l}r g p F \text { gene, } \mathrm{Ap}^{\mathrm{r}} \\
\mathrm{pKS}-\operatorname{rgpF} \text { derivative with an } \mathrm{Sp}^{\mathrm{r}} \text { interposon inserted into the unique } \mathrm{Xba \textrm {I }} \text { site }\end{array}$ & $\ldots$ & This work \\
\hline pBSgFGHI & $\begin{array}{l}\text { of } \operatorname{rgpF}, \mathrm{Ap}^{\mathrm{r}} \mathrm{Sp}^{\mathrm{r}} \\
\mathrm{pKS}^{+} \text {derivative carrying a } 5.6 \mathrm{~kb} \text { Bam } \mathrm{HI}-A p a \mathrm{I} \text { fragment covering a region }\end{array}$ & $\ldots$ & This work \\
\hline & from $r m l B$ to $w b g A, \mathrm{Ap}^{\mathrm{r}}$ & $\ldots$ & Broughton et al. 2006 \\
\hline $\mathrm{pKS}-w b g A$ & $\begin{array}{l}\text { pBSgFGHI derivative in which the } 3.5-\mathrm{kb} X b a \mathrm{I} \text { internal fragment was deleted, } \\
\mathrm{Ap}^{\mathrm{r}}\end{array}$ & $\ldots$ & This work \\
\hline pKS- $w b g A \Omega K m$ & $\begin{array}{l}\text { pKS- } w b g A \text { derivative with an } \Omega \mathrm{Km}^{\mathrm{r}} \text { interposon inserted into the unique } S p h \mathrm{I} \\
\text { site of } w b g A, \mathrm{Ap}^{\mathrm{r}} \mathrm{Km}^{\mathrm{r}}\end{array}$ & $\ldots$ & This work \\
\hline pKS-rgpF pro & $\begin{array}{l}\text { pBluescript KS+ derivative carrying a } 0.57-\mathrm{kb} \text { PCR fragment containing the } \\
\operatorname{rgpF} \text { promoter, } \mathrm{Ap}^{\mathrm{r}}\end{array}$ & . & This work \\
\hline pRK2013 & $\mathrm{Tra}^{+}$helper plasmid & $\ldots$ & Figurski and Helinski 1979 \\
\hline pJQ200SK & Suicide vector used to generate directed mutagenesis, $\mathrm{Gm}^{\mathrm{r}}$ & $\ldots$ & Quandt and Hynes 1993 \\
\hline $\mathrm{pJQ}-l p s B \Omega \mathrm{Sp}$ & pJQ200SK derivative carrying the mutated lps $B \Omega$ Spec fragment, $\mathrm{Gm}^{\mathrm{r}} \mathrm{Sp}^{\mathrm{r}}$ & $\ldots$ & This work \\
\hline pJQ-rgpF $\Omega \mathrm{Sp}$ & pJQ200SK derivative carrying the mutated $\operatorname{rgpF} \Omega$ Spec fragment, $\mathrm{Gm}^{\mathrm{r}} \mathrm{Sp}^{\mathrm{r}}$ & $\ldots$ & This work \\
\hline $\mathrm{pJQ}-w b g A \Omega \mathrm{Km}$ & pJQ200SK derivative carrying the mutated wbgA $\Omega \mathrm{Km}$ fragment, $\mathrm{Gm}^{\mathrm{r}} \mathrm{Km}^{\mathrm{r}}$ & $\ldots$ & This work \\
\hline pJQ $\Omega$ gFGHI & pJQ200SK derivative carrying the disrupted $r m l B$ - $w b g A$ operon, $\mathrm{Gm}^{\mathrm{r}} \mathrm{Km}^{\mathrm{r}}$ & $\ldots$ & Broughton et al. 2006 \\
\hline pPROBE-GT & $\begin{array}{l}\text { Broad-host-range promoter-probe vector containing the green fluorescent } \\
\text { protein open reading frame, } \mathrm{Gm}^{\mathrm{r}}\end{array}$ & & Miller et al. 2000 \\
\hline pPROBE-GT-rgpF & pPROBE-GT derivative containing the $r g p F$ promoter region, $\mathrm{Gm}^{\mathrm{r}}$ & $\ldots$ & This work \\
\hline
\end{tabular}


to verify PCR fidelity. An $\Omega$ interposon conferring resistance to spectinomycin was inserted into the unique $X b a \mathrm{I}$ site and the mutated gene was subcloned using ApaI and SacI restriction sites into the suicide vector pJQ200SK, creating pJQ$\operatorname{rgpF} \Omega \mathrm{Sp}$.

To obtain NGR $\Omega w b g A, \mathrm{pBSgFGHI}$ (Broughton et al. 2006) was digested with $X b a \mathrm{I}$, and the 4.9-kb fragment containing the $\mathrm{N}$-terminal portion of $w b g A$ was religated to create $\mathrm{pKS}$ $w b g A$. An $\Omega$ interposon conferring resistance to kanamycin was inserted into the unique $S p h \mathrm{I}$ site of $\mathrm{pKS}-w b g A$, and the mutated gene was then subcloned into the suicide vector pJQ200SK as an ApaI/XbaI fragment, creating pJQwbgA $\Omega \mathrm{Km}$.

Triparental matings using the helper plasmid pRK2013 (Figurski and Helinski 1979) were used to transfer the resulting suicide plasmids into NGR234. Double recombination was selected by plating bacteria onto TY plates containing 5\% sucrose and appropriate antibiotics. Putative mutants were confirmed by PCR and Southern blots of restricted genomic DNA using standard procedures.

The double mutants NGR $\Delta r m l B$-wbgA $\Omega l p s B$ and NGR $\Delta r m l B$ $w b g A \Omega$ fix $F$ were created by introducing the mutated $\operatorname{lps} B$ gene (i.e., pJQ-lpsB $\Omega \mathrm{Sp}$ ) into NGR $\Delta r m l B-w b g A$ and the disrupted $r m l B$-wbgA operon (i.e. pJQ $\Omega g F G H I)$ into NGR $\Omega$ fix $F$, respectively. Triparental matings, selection, and verification were performed as above.

\section{GFP constructs.}

The promoter region of $r g p F$ was amplified by PCR from genomic DNA of NGR234 using the primers rgpFfor and gM167 and cloned into pBluescript II $\mathrm{KS}^{+}$, then sequenced to verify PCR fidelity. The promoter region was then subcloned into the broad-host-range promoter probe vector, pPROBE-GT (Miller et al. 2000). Plasmids were mobilized from E. coli DH5 $\alpha$ into NGR234 strains by triparental matings, using the helper plasmid pRK2013 (Figurski and Helinski 1979).

\section{Polysaccharide analysis by SDS-PAGE and silver staining.}

Strains were grown in RMS for $40 \mathrm{~h}$, supplemented with $10^{-6}$ $\mathrm{M}$ apigenin when required. Polysaccharide extractions were made from cells collected by centrifuging $4 \mathrm{ml}$ of culture, as described previously (Hitchcock and Brown 1983). Briefly, the cell pellets were resuspended in $30 \mu \mathrm{l}$ of lysis buffer ( $1 \mathrm{M}$ Tris$\mathrm{HCl}$ [pH 6.8], 2\% [wt/vol] SDS, 4\% [vol/vol] $\beta$-mercaptoethanol, $10 \%$ [vol/vol] glycerol, and $0.03 \%$ [wt/vol] bromophenol blue) and boiled for $10 \mathrm{~min}$. Lysed cells were treated with 10 $\mu \mathrm{l}$ of proteinase $\mathrm{K}(2.5 \mathrm{mg} / \mathrm{ml})$ at $60^{\circ} \mathrm{C}$ for $1 \mathrm{~h}$; then, the samples were diluted by adding $80 \mu \mathrm{l}$ of sample buffer $(120 \mathrm{mM}$ Tris- $\mathrm{HCl}$ [pH 6.8], 3\% [wt/vol] SDS, 9\% [vol/vol] $\beta$-mercaptoethanol, $30 \%$ [vol/vol] glycerol, and $0.03 \%$ [wt/vol] bromophenol blue). Polysaccharides were separated by SDS-PAGE (18\% acrylamide) and gels were stained specifically for LPS or KPS as described (Le Quéré et al. 2006).

\section{Nodulation tests.}

Legume seed were obtained from the suppliers listed in Pueppke and Broughton (1999). Nodulation tests were performed in Magenta jars as described by Skorpil and associates (2005). Plants were grown at a day temperature of $28^{\circ} \mathrm{C}$, a night temperature of $18^{\circ} \mathrm{C}$, and a photoperiod of $16 \mathrm{~h}$. Two plants were grown per Magenta jar, each plant being inoculated with $10^{7}$ bacteria. At harvest (6 weeks after inoculation), the aerial portion of the plant was cut and the dry weight recorded. Functional nodules were visually identified by their pink coloration due to the presence of leghaemoglobin. The total number of active (pink) nodules and their fresh weight were determined for each replicate.
Transcriptional analyses with promoter::GFP fusions.

Bacterial strains carrying pPROBE constructs were grown in RMS supplemented with the appropriate antibiotics for $48 \mathrm{~h}$. These precultures were used to inoculate $10 \mathrm{ml}$ of RMS to an optical density at $600 \mathrm{~nm}\left(\mathrm{OD}_{600}\right)$ of 0.1 , and apigenin was added when appropriate. The $\mathrm{OD}_{600}$ and fluorescence (excitation filter at $485 \mathrm{~nm}$ and emission filter at $528 \mathrm{~nm}$ ) from 100 $\mu \mathrm{l}$-aliquots were recorded at $0,24,48$, and $72 \mathrm{~h}$ postinoculation using a Synergy 2 Multi-Mode microplate reader (Bio-Tek Instruments, Winooski, VT, U.S.A.). At least three transcriptional assays were performed for each strain. For the analysis, the fluorescence values obtained were normalized to the average OD at each time point.

\section{LPS purification.}

Strains were grown in 5 liters of RMS supplemented with $10^{-6} \mathrm{M}$ apigenin for $40 \mathrm{~h}$. Cells were harvested by centrifugation at $5,000 \times g$ for $15 \mathrm{~min}$ at $4^{\circ} \mathrm{C}$, then washed twice with $1 \% \mathrm{NaCl}$ and twice with distilled $(\mathrm{d}) \mathrm{H}_{2} \mathrm{O}$. The pellet was resuspended in $50 \mathrm{ml}$ of $\mathrm{dH}_{2} \mathrm{O}$, heated at $65^{\circ} \mathrm{C}$, and then, was mixed with the same volume of hot phenol (at $65^{\circ} \mathrm{C}$ ). The sample was incubated at $65^{\circ} \mathrm{C}$ for $15 \mathrm{~min}$; then, the water and phenol phases were separated by centrifugation at $13,000 \times g$ for $15 \mathrm{~min}$ at $10^{\circ} \mathrm{C}$. A second extraction with the same volume $(50 \mathrm{ml})$ of $\mathrm{dH}_{2} \mathrm{O}$ was performed. The two water phases were mixed, then dialyzed against $\mathrm{dH}_{2} \mathrm{O}$ and lyophilized. The lyophilized material was resuspended (to $15 \mathrm{mg} / \mathrm{ml}$ ) in $0.05 \mathrm{M}$ Tris with $5 \mathrm{mM} \mathrm{MgCl}_{2}, \mathrm{pH} 7.0$, and treated with RNase A (50 $\mu \mathrm{g} / \mathrm{ml}$ at $60^{\circ} \mathrm{C}$ for $3 \mathrm{~h}$ ), DNase I (15 units $/ \mathrm{ml}$ at room temperature for $3 \mathrm{~h})$, and proteinase $\mathrm{K}\left(50 \mu \mathrm{g} / \mathrm{ml}\right.$ at $37^{\circ} \mathrm{C}$ overnight). After exhaustive dialysis against water, the resulting sample was lyophilized. This crude LPS was purified by two steps of size-exclusion chromatography as described previously (Reuhs et al. 2005), except that the order of procedures was reversed. In the first step, $45 \mathrm{mg}$ of sample was dissolved in $1.5 \mathrm{ml}$ of 50 $\mathrm{mM}$ ammonium formate, $\mathrm{pH} 5.0$ and centrifuged at 13,000 $\times \mathrm{g}$ for $10 \mathrm{~min}$ to pellet any insoluble material, and the supernatant was applied to a column $(1.5 \mathrm{~cm}$ in diameter by $90 \mathrm{~cm})$ of Sepharose 4B equilibrated and eluted with this same buffer. Fractions containing LPS as detected by SDS-PAGE were pooled, dialyzed, and lyophilized. In the second step, 6 to 15 $\mathrm{mg}$ of this pooled material (depending on the sample) was soluble in $1.5 \mathrm{ml}$ of buffer containing DOC (Reuhs et al. 2005), and this solution was applied to a Sephadex G-150 column $(1.4 \mathrm{~cm}$ in diameter by $110 \mathrm{~cm})$ equilibrated and eluted with the same DOC buffer. Again, fractions were assayed by SDS-PAGE. Fractions containing a particular LPS gel type were pooled together, dialyzed, and lyophilized. To remove DOC, the samples were dialyzed for three changes against $0.004 \mathrm{M}$ Tris, $0.25 \% \mathrm{NaCl}$, and $10 \%$ ethanol [ $\mathrm{pH} 9.3$ ] and then several changes against water. SDS-PAGE for analyzing fractions in the purification steps was carried out as described previously (Cava et al. 1989) on minigels containing 18\% acrylamide and stained as described (Noel et al. 2004).

\section{LPS composition.}

Sugar and fatty acid compositions of the dry, purified LPS were determined by gas chromatography on an SPB-1 column (Supelco, Bellafonte, PA, U.S.A.) after methanolysis in methanolic $1 \mathrm{M} \mathrm{HCl}$, reaction with trimethylsilyl, and extraction into hexane (Forsberg et al. 2000). The oven temperature was raised $2^{\circ} \mathrm{C} \mathrm{min}{ }^{-1}$ from 150 to $180^{\circ} \mathrm{C}, 1^{\circ} \mathrm{C} \mathrm{min}{ }^{-1}$ from 180 to $200^{\circ} \mathrm{C}$, and $5^{\circ} \mathrm{C} \mathrm{min}^{-1}$ from 200 to $300^{\circ} \mathrm{C}$, and then maintained at $300^{\circ} \mathrm{C}$ for $25 \mathrm{~min}$. Sugars were identified by comparison of retention times with those of authentic standards. Fatty acids were identified by comparing retention times with those of known fatty acids released from purified LPS of $R$. etli, $R$. 
leguminosarum, and Salmonella enterica standard strains, and by reference to the published lipid A structures of NGR234 (Gudlavalleti and Forsberg 2003).

\section{ACKNOWLEDGMENTS}

We thank C. Marie for some preliminary work, Y.-Y. Aung for nodulation tests and plant handling, and D. Gerber for her unstinting help. This work was supported by the Fonds National Suisse de la Recherche Scientifique (projects 3100AO-104097 and 3100A0-116858 to W. J. Broughton and W. J. Deakin), the Département de l'Instruction Publique du Canton de Genève (to W. J. Broughton and W. J. Deakin), the Université de Genève (to W. J. Broughton), and grant DE-FG02-98ER-20307 from the United States Department of Energy (to K. D. Noel).

\section{LITERATURE CITED}

Ausubel, F. M., Brent, R., Kingston, R. E., Moore, D. D., Seidman, J. G., Smith, J. A., and Struhl, K. 1991. Current Protocols in Molecular Biology. John Wiley \& Sons, Inc., New York.

Becker, A., Fraysse, N., and Sharypova, L. 2005. Recent advances in studies on structure and symbiosis-related function of rhizobial Kantigens and lipopolysaccharides. Mol. Plant-Microbe Interact. 18:899905

Beringer, J. E. 1974. R-factor transfer in Rhizobium leguminosarum. J. Gen. Microbiol. 84:188-198.

Broughton, W. J., Wong, C.-H., Lewin, A., Samrey, U., Myint, H., Meyer z. A., H., Dowling, D. N., and Simon, R. 1986. Identification of Rhizobium plasmid sequences involved in recognition of Psophocarpus, Vigna, and other legumes. J. Cell Biol. 102:1173-1182.

Broughton, W. J., Jabbouri, S., and Perret, X. 2000. Keys to symbiotic harmony. J. Bacteriol. 182:5641-5652.

Broughton, W. J., Hanin, M., Relić, B., Kopciñska, J., Golinowski, W., Şimşek, Ş., Ojanen-Reuhs, T., Reuhs, B., Marie, C., Kobayashi, H., Bordogna, B., Le Quéré, A. J.-L., Jabbouri, S., Fellay, R., Perret, X., and Deakin, W. J. 2006. Flavonoid-inducible modifications to rhamnan $\mathrm{O}$ antigens are necessary for Rhizobium sp. strain NGR234-legume symbioses. J. Bacteriol. 188:3654-3663.

Campbell, G. R. O., Reuhs, B. L., and Walker, G. C. 2002. Chronic intracellular infection of alfalfa nodules by Sinorhizobium meliloti requires correct lipopolysaccharide core. Proc. Natl. Acad. Sci. U.S.A. 99:39383943

Cava, J. R., Elias, P. M., Turowski, D. A., and Noel, K. D. 1989. Rhizobium leguminosarum CFN42 genetic regions encoding lipopolysaccharide structures essential for complete nodule development on bean plants. J. Bacteriol. 171:8-15.

Deakin, W. J., and Broughton, W. J. 2009. Symbiotic use of pathogenic strategies: Rhizobial protein secretion systems. Nat. Rev. Microbiol. 7:312-320.

D’Haeze, W., Leoff, C., Freshour, G., Noel, K. D., and Carlson, R. W. 2007. Rhizobium etli CE3 bacteroid lipopolysaccharides are structurally similar but not identical to those produced by cultured CE3 bacteria. J. Biol. Chem. 282:17101-17113.

Fellay, R., Frey, J., and Krisch, H. 1987. Interposon mutagenesis of soil and water bacteria: A family of DNA fragments designed for in vitro insertional mutagenesis of gram-negative bacteria. Gene 52:147-154.

Figurski, D. H., and Helinski, D. R. 1979. Replication of an origin-containing derivative of plasmid RK2 dependent on a plasmid function provided in trans. Proc. Natl. Acad. Sci. U.S.A. 76:1648-1652.

Forsberg, L. S., Bhat, U. R., and Carlson, R. W. 2000. Structural characterization of the O-antigenic polysaccharide of the lipopolysaccharide from Rhizobium etli strain CE3. A unique O-acetylated glycan of discrete size, containing 3-O-methyl-6-deoxy-L-talose and 2,3,4-tri-O,methyl-1 fucose. J. Biol. Chem. 275:18851-18863.

Freiberg, C., Fellay, R., Bairoch, A., Broughton, W. J., Rosenthal, A., and Perret, X. 1997. Molecular basis of symbiosis between Rhizobium and legumes. Nature 387:394-401.

Gibson, K. E., Kobayashi, H., and Walker, G. C. 2008. Molecular determinants of a symbiotic chronic infection. Annu. Rev. Genet. 42:413441.

Gudlavalleti, S. K., and Forsberg, L. S. 2003. Structural characterization of the lipid A component of Sinorhizobium sp. NGR234 rough and smooth form lipopolysaccharide. J. Biol. Chem. 278:3957-3968.

Hitchcock, P. J., and Brown, T. M. 1983. Morphological heterogeneity among Salmonella lipopolysaccharide chemotypes in silver-stained polyacrylamide gels. J. Bacteriol. 154:269-277.

Jones, K. M., Kobayashi, H., Davies, B. W., and Walker, G. C. 2007. How rhizobial symbionts invade plants: The Sinorhizobium-Medicago model.
Nat. Rev. Microbiol. 5:619-633.

Kanipes, M. I., Kalb, S. R., Cotter, R. J., Hozbor, D. F., Lagares, A., and Raetz, C. R. 2003. Relaxed sugar donor selectivity of a Sinorhizobium meliloti ortholog of the Rhizobium leguminosarum mannosyl transferase LpcC. Role of the lipopolysaccharide core in symbiosis of Rhizobiaceae with plants. J. Biol. Chem. 278:16365-16371.

Kannenberg, E. L., and Carlson, R. W. 2001. Lipid A and O-chain modifications cause Rhizobium lipopolysaccharides to become hydrophobic during bacteroid development. Mol. Microbiol. 39:379-391.

Kobayashi, H., Naciri-Graven, Y., Broughton, W. J., and Perret, X. 2004. Flavonoids induce temporal shifts in gene-expression of nod-box controlled loci in Rhizobium sp. NGR234. Mol. Microbiol. 51:335347.

Lagares, A., Hozbor, D. F., Niehaus, K., Otero, A. J., Lorenzen, J., Arnold, W., and Puhler, A. 2001. Genetic characterization of a Sinorhizobium meliloti chromosomal region in lipopolysaccharide biosynthesis. J. Bacteriol. 183:1248-1258.

Le Quéré, A. J.-L., Deakin, W. J., Schmeisser, C., Carlson, R. W., Streit, W. R., Broughton, W. J., and Forsberg, L. S. 2006. Structural characterization of a K-antigen capsular polysaccharide essential for normal symbiotic infection in Rhizobium sp. NGR234. J. Biol. Chem. 281:2898128992.

Marie, C., Deakin, W. J., Ojanen-Reuhs, T., Diallo, E., Reuhs, B., Broughton, W. J., and Perret, X. 2004. TtsI, a key regulator of Rhizobium species NGR234 is required for type III-dependent protein secretion and synthesis of rhamnose-rich polysaccharides. Mol. Plant-Microbe Interact. 17:958-966.

Miller, W. G., Leveau, J. H., and Lindow, S. E. 2000. Improved $g f p$ and inaZ broad-host-range promoter-probe vectors. Mol. Plant-Microbe Interact. 13:1243-1250.

Noel, K. D., Vandenbosch, K. A., and Kulpaca, B. 1986. Mutations in Rhizobium phaseoli that lead to arrested development of infection threads. J. Bacteriol. 168:1392-1401.

Noel, K. D., Forsberg, L. S., and Carlson, R. W. 2000. Varying the abundance of $\mathrm{O}$ antigen in Rhizobium etli and its effect on symbiosis with Phaseolus vulgaris. J. Bacteriol. 182:5317-5324.

Noel, K. D., Box, J. M., and Bonne, V. J. 2004. 2-O-methylation of fucosyl residues of a rhizobial lipopolysaccharide is increased in response to host exudate and is eliminated in a symbiotically defective mutant. Appl. Environ. Microbiol. 70:1537-1544.

Ojeda, K. J., Box, J. M., and Noel, K. D. 2010. Genetic basis for Rhizobium etli $\mathrm{CE} 3 \mathrm{O}$-antigen $\mathrm{O}$-methylated residues that vary according to growth conditions. J. Bacteriol. 192:679-690.

Peterson, A. A., and McGroarty, E. J. 1985. High-molecular-weight components in lipopolysaccharides of Salmonella typhimurium, Salmonella minnesota, and Escherichia coli. J. Bacteriol. 162:738-745.

Poon, K. K., Westman, E. L., Vinogradov, E., Jin, S., and Lam, J. S. 2008. Functional characterization of MigA and WapR: Putative rhamnosyltransferases involved in outer core oligosaccharide biosynthesis of Pseudomonas aeruginosa. J. Bacteriol. 190:1857-1865.

Pueppke, S. G., and Broughton, W. J. 1999. Rhizobium sp. strain NGR234 and $R$. fredii USDA257 share exceptionally broad, nested host ranges. Mol. Plant-Microbe Interact. 12:293-318.

Quandt, J., and Hynes, M. F. 1993. Versatile suicide vectors which allow direct selection for gene replacement in gram-negative bacteria. Gene 127:15-21.

Reuhs, B. L., Kim, J. S., Badgett, A., and Carlson, R. W. 1994. Production of cell-associated polysaccharides of Rhizobium fredii USDA205 is modulated by apigenin and host root extract. Mol. Plant-Microbe Interact. 7:240-247.

Reuhs, B. L., Relić, B., Forsberg, L. S., Marie, C., Ojanen-Reuhs, T., Stephens, S. B., Wong, C. H., Jabbouri, S., and Broughton, W. J. 2005. Structural characterization of a flavonoid-inducible Pseudomonas aeruginosa A-band-like O antigen of Rhizobium sp. strain NGR234, required for the formation of nitrogen-fixing nodules. J. Bacteriol. 187:6479-6487.

Sambrook, J., Fritsch, E. F., and Maniatis, T. 1989. Molecular Cloning: A Laboratory Manual, 2nd ed. Cold Spring Harbor Laboratory Press, Cold Spring Harbor, NY, U.S.A.

Schmeisser, C., Liesegang, H., Krysciak, D., Bakkou, N., Le Quéré, A. Wollherr, A., Heinemeyer, I., Morgenstern, B., Pommerening-Roser, A., Flores, M., Palacios, R., Brenner, S., Gottschalk, G., Schmitz, R. A., Broughton, W. J., Perret, X., Strittmatter, A. W., and Streit, W. R. 2009. Rhizobium sp. strain NGR234 possesses a remarkable number of secretion systems. Appl. Environ. Microbiol. 75:4035-4045.

Skorpil, P., Saad, M. M., Boukli, N. M., Kobayashi, H., Ares-Orpel, F., Broughton, W. J., and Deakin, W. J. 2005. NopP, a phosphorylated effector of Rhizobium sp. strain NGR234, is a major determinant of nodulation of the tropical legumes Flemingia congesta and Tephrosia vogelii. Mol. Microbiol. 57:1304-1317. 
Stanley, J., Dowling, D. N., and Broughton, W. J. 1988. Cloning of hemA from Rhizobium sp. NGR234 and symbiotic phenotype of a genedirected mutant in diverse legume genera. Mol. Gen. Genet. 215:3237.

Wassem, R., Kobayashi, H., Kambara, K., Le Quéré, A. J.-L., Walker, G. C., Broughton, W. J., and Deakin, W. J. 2008. TtsI regulates symbiotic genes in Rhizobium species NGR234 by binding to tts boxes. Mol. Microbiol. 68:736-748.
Whitfield, C. 2006. Biosynthesis and assembly of capsular polysaccharides in Escherichia coli. Annu. Rev. Biochem. 75:39-68.

\section{AUTHOR-RECOMMENDED INTERNET RESOURCE}

National Institute of Technology and Evaluation (NITE) database of biological resources: www.nite.go.jp 